\title{
New Aerogel Products for Construction Use: Product Specifications, Application Examples, Practical Aspects
}

\author{
Eva Günther, ${ }^{1,}$, Marc Fricke ${ }^{2}$, Wibke Lölsberg ${ }^{3}$, Arne Klinkebiel $^{2}$, Dirk Weinrich ${ }^{2}$ \\ ${ }^{1}$ BASF Construction Additives GmbH, Dr.-Albert-Frank-Str. 32, 83033 Trostberg, Germany \\ ${ }^{2}$ BASF Polyurethanes GmbH, Elastogranstr. 60, 49448 Lemförde, Germany \\ ${ }^{3}$ BASF SE, 67056 Ludwigshafen, Germany
}

\begin{abstract}
Two new high-performance insulation materials (HPIM) for the usage in buildings are presented. We show how to use and apply the upcoming aerogel products and give examples for structural details. While both materials achieve very low lambda values due to Knudsen-Effect of aerogels, they differ clearly in other key characteristics. SLENTEX ${ }^{\circledR}$ is a slim, mechanically flexible, non-combustible aerogel mat. It is open for water vapor diffusion but water-repellent. It is suitable for applications with strict fire regulations since it is a purely mineral-based product. SLENTITE ${ }^{\circledR}$ is a homogeneous polyurethane-based aerogel insulation board without lamination or encapsulation layers and also vapor open. Its surface adheres to almost any organic or inorganic binder. It can be processed very much like conventional insulation boards. While their handling and application are very similar to other insulation materials, aerogels are however no general-purpose insulation products: due to their sophisticated production process, and thus higher price compared to conventional insulation products, HPIM are best applied as problem solvers. In well-motivated situations, e.g. where space is limited or particular aesthetic requirements apply, they offer cost effective alternatives to standard solutions.
\end{abstract}

\section{Background and motivation}

From the material technology perspective any insulation product for construction is not just a material that insulates, but that comes with many additional properties such as mechanics, fire rating, vapor diffusivity, water uptake, workability, durability - their relevance prioritized depending on the individual application needs. As there is no single perfect material, a large portfolio of insulation products for construction exists on the market today, and $R \& D$ of new products is ever ongoing [1,2,3].

From the market perspective, the need for renovation of residential buildings is still massive. In Germany, by 2050 , the primary energy requirement in this area is to be reduced by $80 \%$, and the renovation rate is to be doubled accordingly [4]. In retrofit objects, where thick exterior insulation or other routes to optimize energy efficiency (e.g. solar architecture) are not readily accessible, slim and practical insulation solutions could have a significant impact to reach efficiency targets and match design needs.

The goal of our development was therefore a commercial product with a very low thermal conductivity in combination with easy to handle properties.

High performance insulation materials (HPIM), i.e. materials with inferior thermal conductivity compared to still air (lambda $<0.027 \mathrm{~W} / \mathrm{m} \cdot \mathrm{K}$ ) are found in three categories: (1) tight closed-pore foams such as polyisocyanurate (PIR) and phenolic resin foams that rely on lower conductivity of exchange-gas, (2) vacuum insulation panels (VIP) that achieve low lambda by reducing air concentration and thus air conduction, and (3) aerogel materials benefitting from the Knudsen effect that results in suppressed air conductivity in nanosized structures. Aerogels inherently do not alter their conductivity by gas emission or gas uptake, that means, aerogel has not to be sealed to maintain its thermal performance. With respect to building applications, this has two major advantages: aerogel products can be cut and can be vapor-open. Both abilities are of major interest from practical and construction physical reasons. This is why our product development focused on the aerogel material class.

As to the workability on site, very different requirements could not be achieved by one aerogel product. Instead, two different specifications were addressed in the form of two new products: an inorganic aerogel in mat form $\left(\right.$ SLENTEX $\left.^{\circledR}\right)$ [5], and an organic aerogel in solid panel form $\left(\right.$ SLENTITE $\left.^{\circledR}\right)$ [6].

\section{Product description}

\subsection{SLENTEX ${ }^{\circledR}$}

SLENTEX $^{\circledR}$ is a flexible insulation mat based on silica aerogel and glass fiber. It is non-burning, open to water vapor diffusion and water repellent (hydrophobized). The material is $10 \mathrm{~mm}$ thick and produced in rolls of $150 \mathrm{~cm}$ width and approx. $45 \mathrm{~m}$ length. See illustration in Fig. 1 and the main product properties in Table 1 . 


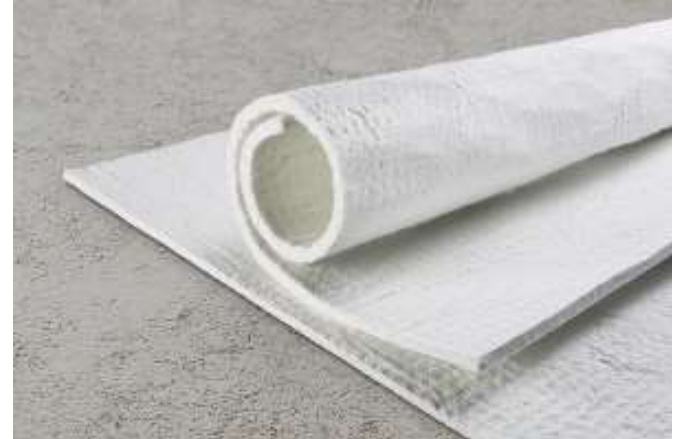

Fig. 1. SLENTEX ${ }^{\circledR}$ roll (piece).

\subsection{SLENTITE ${ }^{\circledR}$}

SLENTITE $^{\circledR}$ is a polyurethane aerogel insulating panel, see Fig. 2. It is produced in $55 \mathrm{~cm} \times 36 \mathrm{~cm}$ sized panels of $15 \mathrm{~mm}$ thickness, is light-weight, mechanically robust based and easy to handle and combine with other materials. It is a ready-to-use product delivered in boxes of 20 pieces and less than $10 \mathrm{~kg}$ gross weight, so it can be easily transported even to remote sites. The main product properties are listed in Table 1.

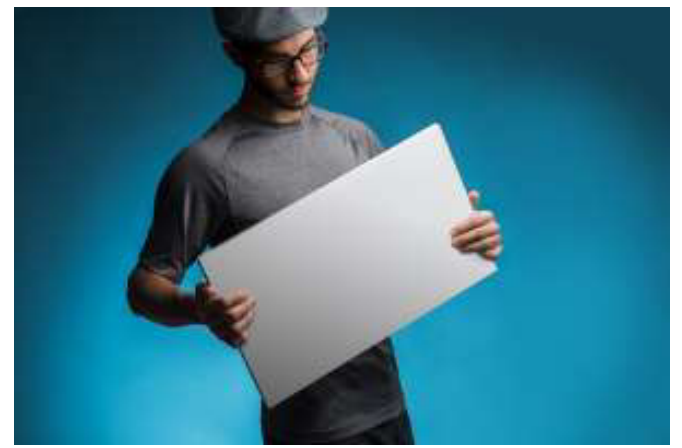

Fig. 2. Slentite panel.

Table 1. Main product properties compared.

\begin{tabular}{|c|c|c|}
\hline & SLENTITE $^{\circledR}$ & SLENTEX $^{\circledR}$ \\
\hline $\begin{array}{l}\lambda \text {-value (thermal } \\
\text { conductivity) }\end{array}$ & $\begin{array}{r}0.018 \mathrm{~W} / \mathrm{m} \cdot \mathrm{K} \\
(\mathrm{EN} 12667)\end{array}$ & $\begin{array}{r}\lambda_{\mathrm{D}}=0.019 \mathrm{~W} / \mathrm{m} \cdot \mathrm{K} \\
(\mathrm{EN} 13162)\end{array}$ \\
\hline thickness & $15 \mathrm{~mm}$ & $10 \mathrm{~mm}$ \\
\hline R-value & $0.83 \mathrm{~m}^{2} \cdot \mathrm{K} / \mathrm{W}$ & $0.53 \mathrm{~m}^{2} \cdot \mathrm{K} / \mathrm{W}$ \\
\hline U-value & $1.2 \mathrm{~W} / \mathrm{m}^{2} \cdot \mathrm{K}$ & $1.9 \mathrm{~W} / \mathrm{m}^{2} \cdot \mathrm{K}$ \\
\hline $\begin{array}{l}\mu \text {-value (water } \\
\text { vapor diffusivity) }\end{array}$ & $(\mathrm{EN} \mathrm{12086)}$ & 5 \\
\hline $\begin{array}{l}\text { density } \\
\text { (EN 1602) }\end{array}$ & $110-135 \mathrm{~g} / \mathrm{m}^{3}$ & $190-200 \mathrm{~kg} / \mathrm{m}^{3}$ \\
\hline tensile strength & $>100 \mathrm{kPa}$ & $\begin{array}{r}16 \mathrm{kPa} \\
(\mathrm{EN} \mathrm{1607)}\end{array}$ \\
\hline $\begin{array}{l}\text { compressive } \\
\text { strength }\end{array}$ & $\begin{array}{r}\geq 300 \mathrm{kPa} \\
(\text { ISO } 844)\end{array}$ & $\begin{array}{r}30 \mathrm{kPa} @ 10 \% \\
(\mathrm{EN} \mathrm{826)}\end{array}$ \\
\hline reaction to fire & $\begin{array}{r}\text { class E } \\
(\mathrm{EN} \mathrm{11925-2})\end{array}$ & $\begin{array}{r}\mathrm{A} 2-\mathrm{s} 1, \mathrm{~d} 0 \\
(\mathrm{EN} 13501-1)\end{array}$ \\
\hline
\end{tabular}

\section{Application guidelines}

\subsection{SLENTEX ${ }^{\circledR}$}

SLENTEX $^{\circledR}$ can be cut with standard tools, most simply with a cutter knife, jig saw or band saw. Best results are obtained with waved blades for soft materials; crossed teeth blades should be avoided as they tend to tear the material up, see Fig. 3.

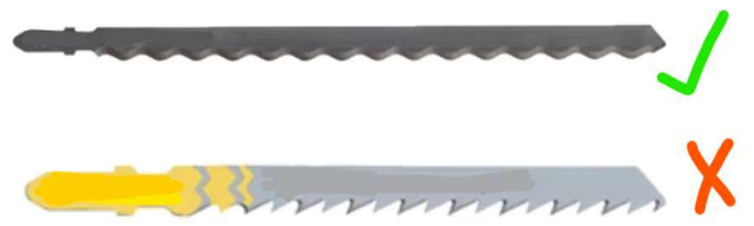

Fig. 3. To cut SLENTEX ${ }^{\circledR}$, use blades with smooth waved teeth (top), avoid crossed and edgy teeth (bottom).

Wear safety glasses and protective clothing when working with SLENTEX $^{\circledR}$ and be aware to follow standard recommendations for processing dusty material. For more details, please consult the product safety data sheet.

If necessary, multiple layers of SLENTEX ${ }^{\circledR}$ can be glued together using appropriate adhesive. The choice of adhesive and application amount may influence the properties of multi-layered SLENTEX ${ }^{\circledR}$ such as fire behaviour, thermal conductivity, water vapor permeability and mechanical properties.

Following are some possible adhesive options:

- polyurethane based glue, or other organic adhesives

- potassium water glass, avoid using sodium water glass

- commercially available non-combustible adhesives

- cement or geopolymer based binder

The adhesion quality will depend on the material selection, but also on the process. This is true both in manufacturing a multilayer insulation workpiece, as well as in applicating the insulation at the construction site. Following are few general recommendations on the gluing process:

- If excess dust is present on SLENTEX ${ }^{\circledR}$ surface, it is recommended to use adequate dust extraction to allow good bonding between layers.

- Depending on the selected adhesive type, application of adhesive on one or both layer surfaces, and full-area or part-area distribution of adhesive on surface can lead to desired bonding strength.

- Application of pressure and/or heat treatment during the adhesive curing may be required. Microwave may be used for efficient drying in industrial production scale.

Figures 4 to 6 illustrate the workflow of applying SLENTEX $^{\circledR}$ to a wall using a cement based binder (glue mortar). 


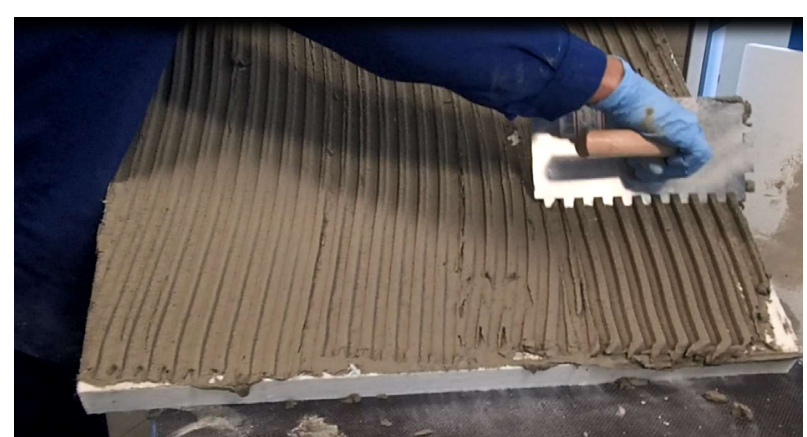

Fig. 4: Application of cement-based binder on SLENTEX ${ }^{\circledR}$

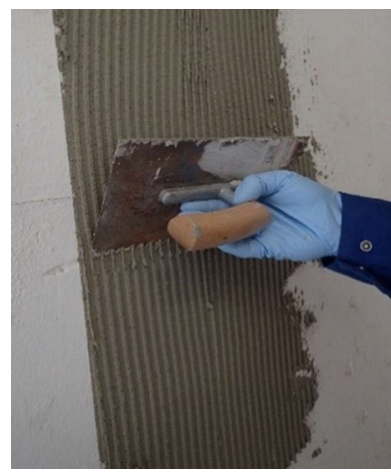

Fig. 5: Application of adhesive on the wall

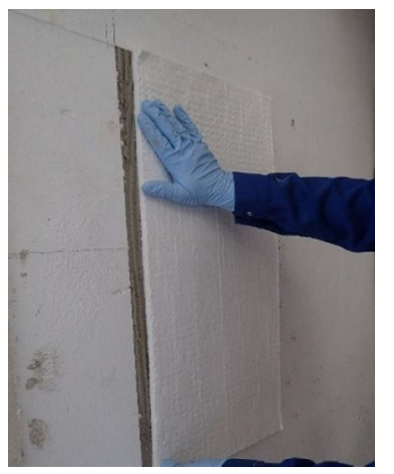

Fig. 6: Application of SLENTEX $^{\circledR}$ panel with adhesive on the wall
Mechanical fixing of SLENTEX ${ }^{\circledR}$ e.g. in sandwiched and clamped structures is another option to apply the material. Its flexibility supports curved geometries and its spring-back allows to integrate it void-free in cassette constructions and the like. It can be stapled to wood-based construction panels without problems, see Fig. 7.

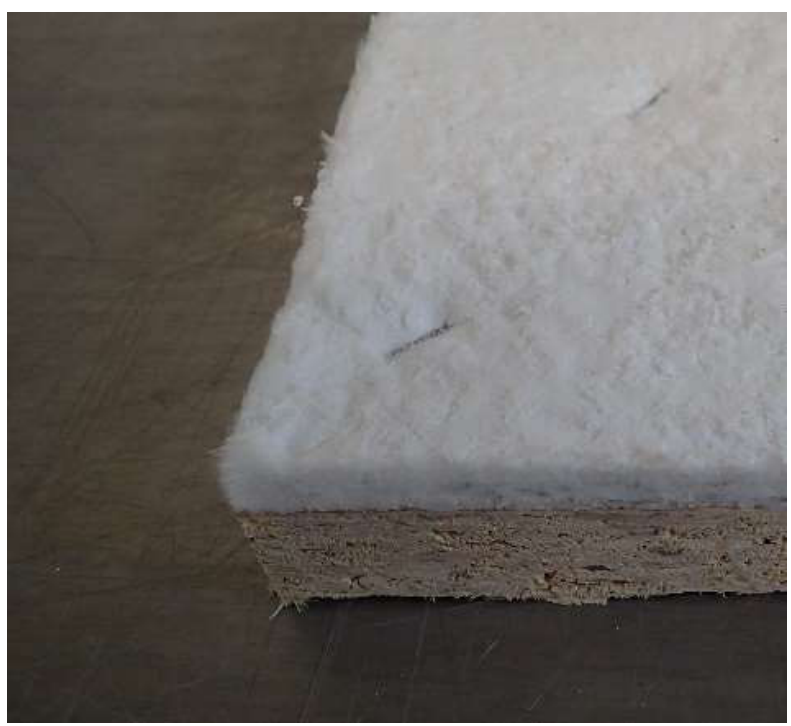

Fig. 7: Slentex stapled to OSB.

\subsection{SLENTITE ${ }^{\circledR}$}

For cutting, SLENTITE ${ }^{\circledR}$ insulation panels are placed on a solid, even surface. Typically, a cutter knife is used for cutting (see Fig. 8). The panels are scratched along a ruler and then broken over the edge. If required, the edges can be smoothed using a planer tool or rough sandpaper. Standard tools such as core drills can be used to shape details where required.
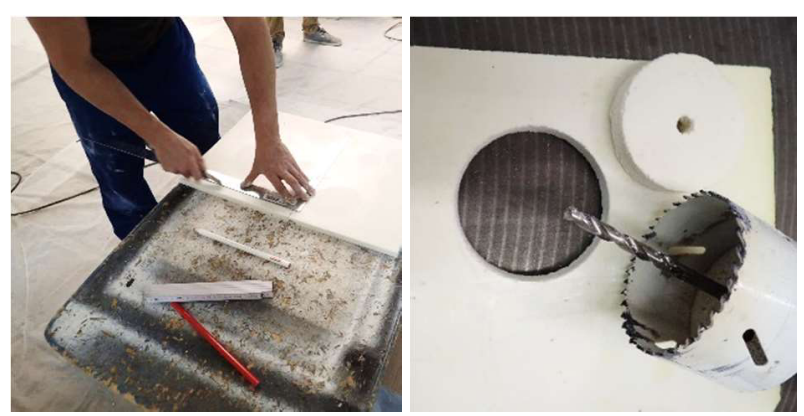

Fig. 8: Cutting SLENTITE ${ }^{\circledR}$ straight and circular

Despite its strong mechanical properties, the panels should be handled with care. In particular, a damage of the edges should be prevented:

- don't throw or let drop the panels

- use both hands to pick up panels, completely grasping at two edges

- don't hit panels on edges, bend or compress them.

SLENTITE $^{\circledR}$ is compatible with most kinds of materials, as some typical examples in the following illustrate (Fig. 9). The solid surface with its fine porosity is an easy substrate for liquids, pastes and viscous materials, as well as for tapes and foams of various types. Avoid contact to organic solvents, as this might damage the product.
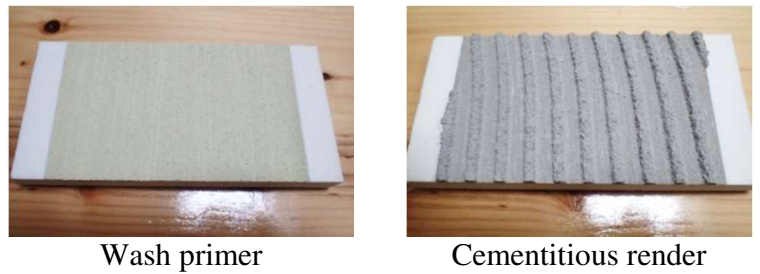

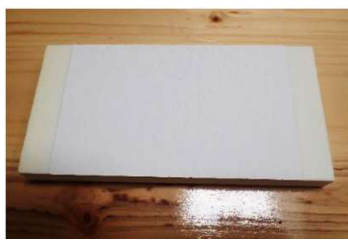

Washable interior paint

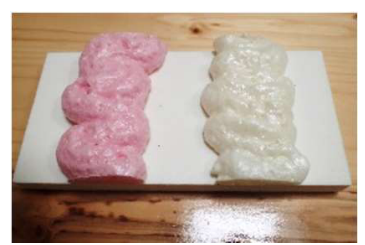

PU foam sealants
Fig. 9 : A few exemplary materials applied on SLENTITE ${ }^{\circledR}$.

\section{Application cases of HPIM}

\subsection{HPIM versus standard insulation}

To illustrate the range of possible HPIM solutions, a simplified building envelope insulation is discussed in the following example. In Figure 10, general options of arranging an HPIM insulation layer compared to a standard insulation material are sketched. 


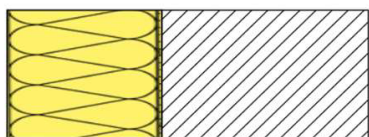

A

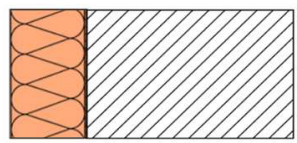

$B$

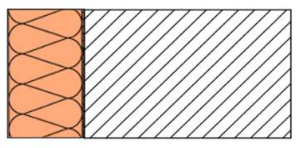

C
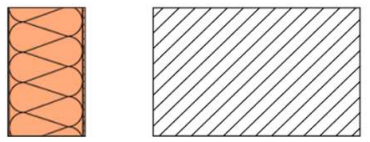

D

ext

int

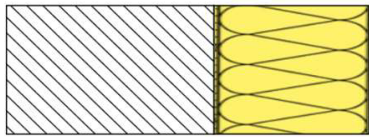

$E$

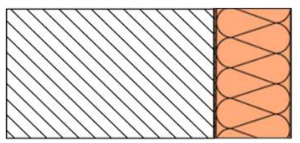

$\mathrm{F}$

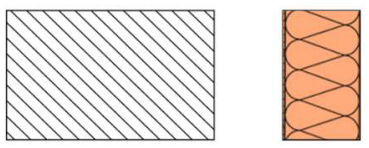

G

Fig. 10: Schematic cross sections of a solid wall (left: exterior, right: interior) with conventional exterior insulation (A) versus HPIM options (B-D); conventional interior insulation (E) versus HPIM options (F-G).

For exterior insulation, compared to the reference case (A), there are several options. The layer thickness of the building envelope can be reduced (B), which can be crucial in a façade retrofit avoiding the need to change the roof overhang, or where a traffic area next to the building strictly limits its boundary line. Keeping the building silhouette unchanged to the reference case, HPIM allows to move the solid wall outwards and thus creates more space for indoor floor area (C). In another variant, HPIM frees space between insulation and solid wall (D), that can be used for installation of piping or façade components such as moveable shading elements.

As to interior insulation (E-G), similar inverted variants apply. The solid wall is generally considered fixed in position, as interior insulation is mainly done in retrofit objects. Here, variant $(\mathrm{F})$ corresponds to gained indoor space and variant $(\mathrm{G})$ gives room for an installation channel or the like.

\subsection{Field of application of the two products}

SLENTEX $^{\circledR}$ is suitable for exterior and interior details to minimize thermal bridges. Also, it can be applied for optimization of the thermal performance within facade systems. Examples are thermal decoupling of ventilated facade elements, ventilated facade insulation boards and insulation for exterior insulation finishing systems (EIFS). This material is mechanically flexible, it can be bent and compressed, e.g. to follow curvy shapes or to fit in sandwiched arrangements. It tolerates temporary exposition to humidity as it is hydrophobic and vapor open but should as any insulation layer be protected from constant elevated humidity levels that would reduce its thermal performance.

SLENTITE $^{\circledR}$ is suitable from interior and exterior as reveal thermal insulation as well as application as core for window profiles and roller shutter casings. It is an ideal material for areas with space constraints. It is rigid, can be processed to shape and can be applied under static load with minimum change in dimension. This material is not hydrophobic and needs to be located appropriately within the building cross section. It can be applied where protected by a waterproofing layer or in vapor open construction variants. A detailed report on two field test cases where SLENTITE $^{\circledR}$ was applied as interior insulation in heritage buildings is given in our second paper [7].

\subsection{Field case exemplary detail solutions}

In a full area / flat wall application, the obvious benefit of HPIM is the reduced dimension of the insulation layer compared to standard insulation materials. In detail solutions, there can be additional and other benefits, as individual as buildings and building usages. Here, to trigger the imagination of building owners, architects, engineers, craftsmen, just a few examples are illustrated in the following.

In the façade of the laboratory building as shown in figure 11, HPIM was applied in the area of the roller shutter boxes to allow a smooth surface without thermal bridges, in combination with a conventional EIFS based on mineral wool in the regular cross section.

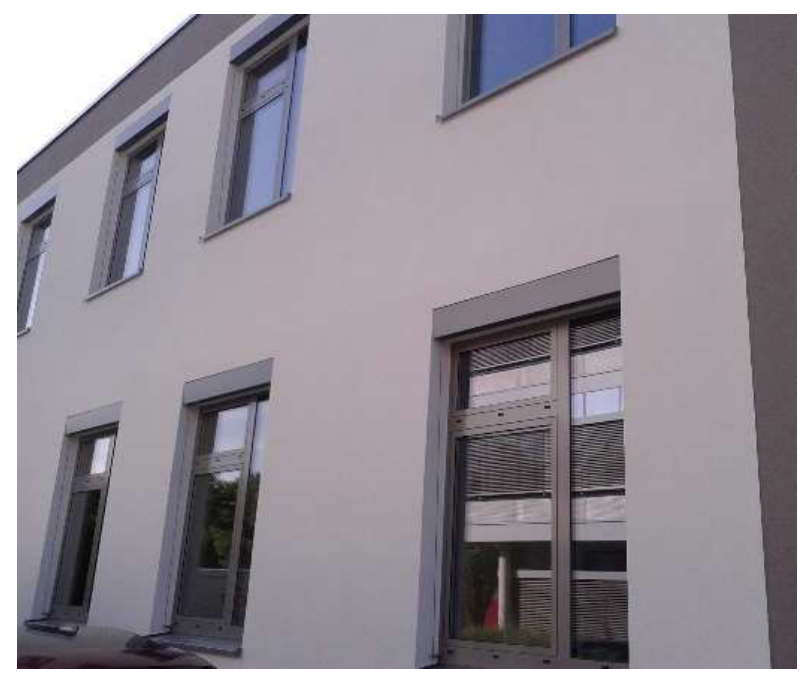

Fig. 11: Façade aligned roller shutter boxes with rearward HPIM stripes to avoid thermal bridges $\left(\right.$ SLENTEX $\left.^{\circledR}\right)$

In the context of the refurbishment of a large housing unit, the regular façade was insulated with an EPS based EIFS, and HPIM was applied in the rear wall area of the balconies as shown in figure 12. Like this, their 
accessibility was maintained without need to extend or reposition the balconies.

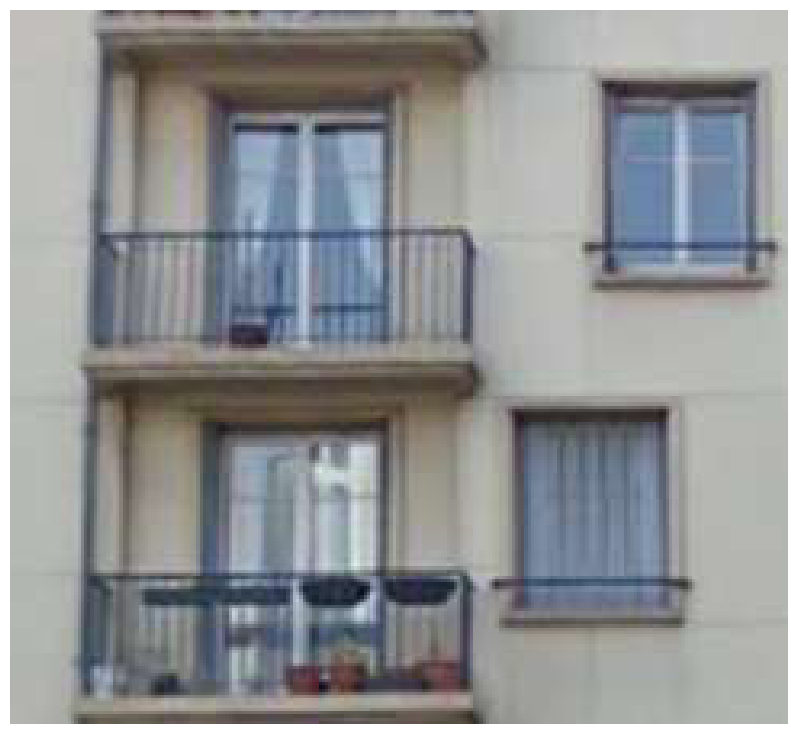

Fig. 12: HPIM to conserve usability of small balconies after energetic retrofit by EIFS (SLENTEX ${ }^{\circledR}$ ).

Another exemplary benefit is illustrated in figure 13 . The main target of the interior insulation of this heritage building was not to reach passive house standards, but to significantly reduce energy demand and mitigate condensation problems while conserving the architectural appearance. Here, a slim HPIM insulation was applied on the interior side of the outer wall and the same on the window jambs, working around hinge details and with minimum effect on natural light incidence.

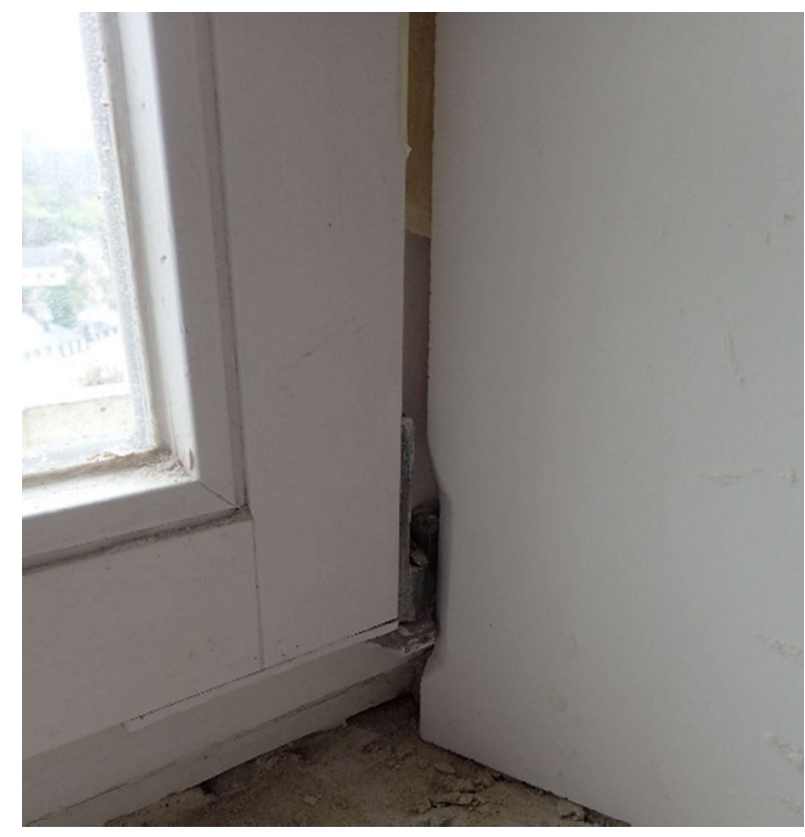

Fig. 13: HPIM enables retrofitting the interior window jamb in very limited space $\left(\right.$ SLENTITE $^{\circledR}$ )

A final detail example is illustrated in figure 14: in this heritage brickwork building with a cavity wall, the original interior could mostly be conserved including the historic radiator. The heat loss through the thin wall in the area below the window could be significantly reduced by applying HPIM on the interior wall in the niche behind the radiator.

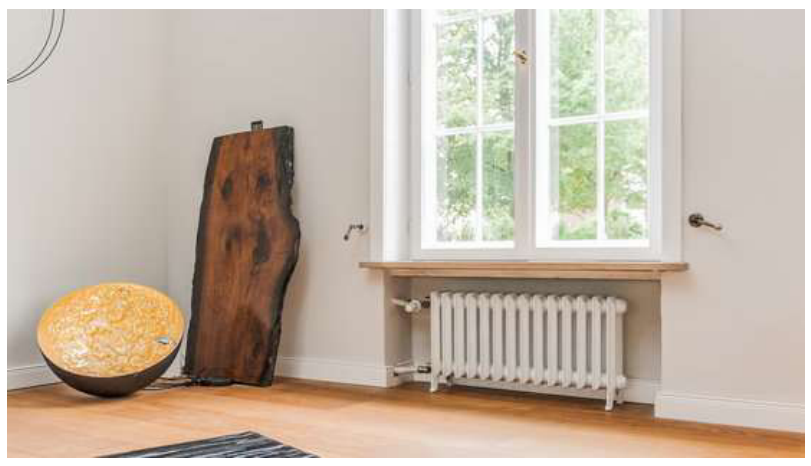

Fig. 14 : HPIM permits interior insulation of heating niche in a heritage building (SLENTITE ${ }^{\circledR}$ )

\section{Discussion}

We present two high-performance insulation material (HPIM) products that can be applied very much like conventional insulation products. There is a huge need for insulation materials in construction worldwide. The primary concerns about HPIM are durability, material costs, and workability.

As aerogel materials, durability is not dependent on gas diffusion processes, but can be assured by structural integrity of the constituting materials (silica in SLENTEX $^{\circledR}$ and polyurethane in SLENTITE $^{\circledR}$ ). The materials can be cut and processed easily without concerns of performance loss.

As high-tech materials, HPIMs are more expensive in production and market price than conventional insulation materials. Material costs can be confronted with material benefits to decide which type of solution is preferred. When material costs are compared based on volume and price per volume, improved insulation materials pay off only if their price raises less than lambda falls. From this point of view, HPIM are clearly not cost-efficient compared to standard insulation options. But from a wider perspective, other arguments in favour of HPIM can become very relevant, such as:

- Value of saved space - In scenarios where space is limited and expensive, the value of space gained can easily exceed the additional costs of applying HPIM. A typic example is interior insulation that directly reduces indoor area, but also exterior insulation reduces indoor area where property limits are reached.

- Avoided cost of auxiliary work - in scenarios where conventional insulation can only be applied in combined actions e.g. of substituting windows, changing stairs or fire rescue pathways, a solution that does not trigger such extra measures will save a lot of trouble and money. This view is supported e.g. by the IEA technology roadmap on energy efficient building envelopes [8].

As to workability, the presented products both have their own handling characteristics as sketched above. 


\section{References}

1. M. Pfundstein et al., Dämmstoffe (Detail Verlag 2007) ISBN 978-3-95553-021-1

2. Schiavoni et al., Renewable and Sustainable Energy Reviews 62 (2016) 988-1011

3. H. F. Gangåssæter et al., Energy Procedia 132 (2017) $231-236$

4. dena (2017) Gebäudestudie: Szenarien für eine marktwirtschaftliche Klima- und Ressourcenschutzpolitik 2050 im Gebäudesektor, Deutsche Energie Agentur GmbH (German Energy Agency), Berlin

https://www.dena.de/fileadmin/dena/Dokumente/Pd f/9220 Gebaeudestudie Szenarien Klimaund Ressourcenschutzpolitik 2050.pdf

5. SLENTEX ${ }^{\circledR}$ product web site $\underline{w w w . s l e n t e x . c o m}$

6. SLENTITE ${ }^{\circledR}$ product web site www.slentite.com

7. E. Günther, S. Bichlmair, S. Latz, M. Fricke: Internal wall insulation with a new aerogel panel: SLENTITE for energetic retrofit in historic buildings, to be published at NSB2020, paper \#299

8. IEA (2013), Technology Roadmap - Energy Efficient Building Envelopes, IEA, Paris https://www.iea.org/reports/technology-roadmapenergy-efficient-building-envelopes 